\title{
On optimal head starts in all-pay auctions
}

Citation for published version (APA):

Seel, C., \& Wasser, C. (2014). On optimal head starts in all-pay auctions. Economics Letters, 124(2), 211214. https://doi.org/10.1016/j.econlet.2014.05.018

Document status and date:

Published: 01/08/2014

DOI:

10.1016/j.econlet.2014.05.018

Document Version:

Publisher's PDF, also known as Version of record

Document license:

Taverne

Please check the document version of this publication:

- A submitted manuscript is the version of the article upon submission and before peer-review. There can be important differences between the submitted version and the official published version of record.

People interested in the research are advised to contact the author for the final version of the publication, or visit the DOI to the publisher's website.

- The final author version and the galley proof are versions of the publication after peer review.

- The final published version features the final layout of the paper including the volume, issue and page numbers.

Link to publication

\footnotetext{
General rights rights.

- You may freely distribute the URL identifying the publication in the public portal. please follow below link for the End User Agreement:

www.umlib.nl/taverne-license

Take down policy

If you believe that this document breaches copyright please contact us at:

repository@maastrichtuniversity.nl

providing details and we will investigate your claim.
}

Copyright and moral rights for the publications made accessible in the public portal are retained by the authors and/or other copyright owners and it is a condition of accessing publications that users recognise and abide by the legal requirements associated with these

- Users may download and print one copy of any publication from the public portal for the purpose of private study or research.

- You may not further distribute the material or use it for any profit-making activity or commercial gain

If the publication is distributed under the terms of Article $25 \mathrm{fa}$ of the Dutch Copyright Act, indicated by the "Taverne" license above, 


\title{
On optimal head starts in all-pay auctions
}

\author{
Christian Seel ${ }^{\mathrm{a}}$, Cédric Wasser ${ }^{\mathrm{b}, *}$ \\ a Maastricht University, School of Business and Economics, Tongersestraat 53, P.O. Box 616, 6200 MD Maastricht, The Netherlands \\ ${ }^{\mathrm{b}}$ University of Bonn, Department of Economics, Lennéstr. 37, 53113 Bonn, Germany
}

\section{H I G H L I G H T S}

- We consider a two-player all-pay auction in which the designer chooses a head start.

- The designer maximizes a convex combination of the expected total and highest effort.

- Unless the weight on the highest effort is 1 , small head starts are worse than none.

- A positive head start is optimal iff the weight on the highest effort is large enough.

\section{A R T I C L E I N F O}

\section{Article history:}

Received 16 April 2014

Accepted 21 May 2014

Available online 29 May 2014

\section{JEL classification:}

C72

D44

D74

D82

Keywords:

Contest

All-pay auction

Head start

\begin{abstract}
A B S T R A C T
We consider a two-player all-pay auction with symmetric independent private values that are uniformly distributed. The designer chooses the size of a head start that is given to one of the players. The designer's objective is to maximize a convex combination of the expected highest effort and the expected aggregate effort. Unless the weight on the highest effort is one, small head starts are always worse than no head start. Moreover, the optimal head start is strictly positive if and only if the weight on the highest effort is large enough.
\end{abstract}

(C) 2014 Elsevier B.V. All rights reserved.

\section{Introduction}

Contests are among the most frequently used mechanisms with applications in job promotion, procurement, competitions for grants or college admission, innovation, R\&D, sports and so forth. The organizer of a contest often directly or indirectly benefits from the effort that participants invest. Hence, natural objectives when designing a contest are to maximize the expected aggregate effort or the expected highest effort. The latter objective is, for instance, particularly relevant in innovation contests where the organizer plans to implement only the best innovation, e.g., the best of the prototypes or algorithms that are submitted by the participants. Another example is a firm that adopts the most creative advertising campaign out of several proposals.

\footnotetext{
* Corresponding author.

E-mail addresses: c.seel@maastrichtuniversity.nl (C. Seel), cedric.wasser@uni-bonn.de (C. Wasser).
}

Surprisingly, the contest literature has mainly focused on the problem of maximizing aggregate effort. A common finding is that if contestants are asymmetric in their abilities, it is beneficial for the designer to bias the contest in favor of weaker participants: leveling the playing field enhances competition and thereby elicits more effort. However, if contestants are symmetric, the designer typically prefers an unbiased contest; see, e.g., Lazear and Rosen (1981), Clark and Riis (2000), Kirkegaard (2012), and Franke et al. (2014).

In this paper, we examine whether this conclusion remains to hold if the designer is - either exclusively or at least partially interested in maximizing the expected highest effort. We consider an all-pay auction with two ex ante symmetric players that are privately informed about their uniformly distributed valuations. The designer can choose the size of a head start (Konrad, 2002; Seel, 2014; Siegel, 2014) that is granted to one of the players. This player wins whenever the sum of her effort and the head start is higher than the other player's effort. Whereas any nonzero head start reduces the expected aggregate effort in our setting, we show that the optimal head start is strictly positive if the expected highest 
effort is sufficiently important to the designer. Hence, the common intuition of leveling the playing field does not necessarily apply.

Two recent papers show that unequal treatment of ex ante symmetric players can be beneficial if the designer is not or not only interested in the efforts of the contestants. Kawamura and Moreno de Barreda (2014) find that a head start may increase the probability of selecting the highest ability player in an allpay auction that is played under complete information. PérezCastrillo and Wettstein (2013) study innovation contests where the quality of a player's innovation is a function of his privately known type and his effort. They show that the designer may profit from discriminating among contestants by letting the size of the prize vary with the winner's identity.

\section{Model and preliminaries}

There are two players $i=1,2$ competing for a single prize. Each player $i$ privately knows his valuation for the prize $v_{i}$, which is a realization of the random variable $V_{i}$. The random variables $V_{1}$ and $V_{2}$ are identically and independently distributed according to the continuous cumulative distribution function $F$. They have a strictly positive density $f$ on their support $[0, \bar{v}]$. The virtual valuation function

$\psi(v):=v-\frac{1-F(v)}{f(v)}$ is strictly increasing in $v$.

Players compete in a first-price all-pay auction. Player 1 enjoys a head start $a \in[0, \bar{v}],{ }^{1}$ i.e., he wins if $b_{1}+a>b_{2}$ and player 2 wins if $b_{1}+a \leq b_{2}$, where $b_{i}$ denotes the bid (invested effort) of player $i$. The (ex post) payoff of player $i$ is $v_{i}-b_{i}$ if he wins and $-b_{i}$ otherwise. A pure strategy for player $i$ is a function $\beta_{i}:[0, \bar{v}] \rightarrow \mathbb{R}_{+}$ so that player $i$ bids $\beta_{i}\left(v_{i}\right)$ if his valuation is $v_{i}$.

From Kirkegaard (2012) it follows that in the Bayesian Nash equilibrium of this game for a given head start $a$, players use the equilibrium strategies

$\beta_{1}^{a}(v):= \begin{cases}0 & \text { if } v<\hat{v}, \\ \int_{\hat{v}}^{v} x \mathrm{~d} F(x) & \text { if } v \geq \hat{v},\end{cases}$

$\beta_{2}^{a}(v):= \begin{cases}0 & \text { if } v<\hat{v}, \\ a+\int_{\hat{v}}^{v} x \mathrm{~d} F(x) & \text { if } v \geq \hat{v},\end{cases}$

where $\hat{v}$ is implicitly defined by $a=\hat{v} F(\hat{v})$.

Note that for $a>0,0=\beta_{1}^{a}(v)=\beta_{2}^{a}(v)<\beta_{1}^{0}(v)=\beta_{2}^{0}(v)$ for $v<\hat{v}$ whereas $0<\beta_{1}^{a}(v)<\beta_{1}^{0}(v)=\beta_{2}^{0}(v)<\beta_{2}^{a}(v)$ for $v>\hat{v}$. A head start for player 1 induces both players to exert zero effort for low valuations. For high valuations, the head start leads to player 2 bidding more aggressively and player 1 bidding less aggressively compared to the benchmark without a head start.

The contest designer's objective is to maximize a weighted sum of the expected highest effort and the expected average effort ${ }^{2}$ :

$$
\begin{aligned}
W_{\gamma}(a):= & \gamma E\left[\max \left\{\beta_{1}^{a}\left(V_{1}\right), \beta_{2}^{a}\left(V_{2}\right)\right\}\right] \\
& +(1-\gamma) E\left[\frac{1}{2}\left(\beta_{1}^{a}\left(V_{1}\right)+\beta_{2}^{a}\left(V_{2}\right)\right)\right]
\end{aligned}
$$

\footnotetext{
1 We exclude head starts $a>\bar{v}$ from the analysis to avoid the trivial equilibrium in which both players always bid zero.

2 Note that maximizing $W_{\gamma}$ is equivalent to maximizing the weighted sum of the expected highest effort (weight $\gamma^{\prime}$ ) and the expected total effort (weight $1-\gamma^{\prime}$ ) for $\gamma=\frac{\gamma^{\prime}}{2-\gamma^{\prime}}$.
}

where $\gamma \in[0,1]$. We denote optimal head starts by $a^{*}(\gamma):=$ $\arg \max _{a} W_{\gamma}(a)$.

First, consider $\gamma=0$ such that the objective is the expected average effort

$W_{0}(a)=\frac{1}{2} \hat{v} F(\hat{v})(1-F(\hat{v}))+\int_{\hat{v}}^{\bar{v}} \int_{\hat{v}}^{v} x \mathrm{~d} F(x) \mathrm{d} F(v)$.

Taking the derivative with respect to $a$, we find

$$
\begin{aligned}
W_{0}^{\prime}(a) & =\frac{\mathrm{d} \hat{v}}{\mathrm{~d} a}\left(-\frac{1}{2} \hat{v}(1-F(\hat{v})) f(\hat{v})-\frac{1}{2} \psi(\hat{v}) F(\hat{v}) f(\hat{v})\right) \\
& =\frac{\mathrm{d} \hat{v}}{\mathrm{~d} a} \frac{1}{2} \int_{0}^{\hat{v}}(\psi(x)-\psi(\hat{v})) f(x) f(\hat{v}) \mathrm{d} x,
\end{aligned}
$$

where we have used that $\int \psi(x) f(x) \mathrm{d} x=-x(1-F(x))$. Since $a=\hat{v} F(\hat{v}), \frac{\mathrm{d} \hat{v}}{\mathrm{~d} a}>0$. Together with assumption (1), this implies $W_{0}^{\prime}(a)<0$ for all $a>0$. Hence, if $\gamma=0$, it is not beneficial to introduce a head start, i.e., $a^{*}(0)=0$. $^{3}$

Now, consider $\gamma=1$ such that the objective is the expected highest effort. To determine $W_{1}(a)$ from the equilibrium strategies, observe that from an ex ante perspective, player $i$ 's bid $b_{i}$ is distributed according to $F\left(\left(\beta_{i}^{a}\right)^{-1}\left(b_{i}\right)\right)$. Let $X_{a}:=$ $\max \left\{\beta_{1}^{a}\left(V_{1}\right), \beta_{2}^{a}\left(V_{2}\right)\right\}$ be the highest bid and let $G_{a}$ denote the cumulative distribution function of $X_{a}$ with support $\left[0, \beta_{2}^{a}(\bar{v})\right]$. If $0 \leq$ $a \leq \beta_{1}^{a}(\bar{v})$

$$
G_{a}(x)= \begin{cases}F(\hat{v})^{2} & \text { if } x=0, \\ F\left(\left(\beta_{1}^{a}\right)^{-1}(x)\right) F(\hat{v}) & \text { if } x \in(0, a), \\ F\left(\left(\beta_{1}^{a}\right)^{-1}(x)\right) F\left(\left(\beta_{2}^{a}\right)^{-1}(x)\right) & \text { if } x \in\left[a, \beta_{1}^{a}(\bar{v})\right), \\ F\left(\left(\beta_{2}^{a}\right)^{-1}(x)\right) & \text { if } x \in\left[\beta_{1}^{a}(\bar{v}), \beta_{2}^{a}(\bar{v})\right],\end{cases}
$$

whereas if $\beta_{1}^{a}(\bar{v})<a<\bar{v}$,

$$
G_{a}(x)= \begin{cases}F(\hat{v})^{2} & \text { if } x=0, \\ F\left(\left(\beta_{1}^{a}\right)^{-1}(x)\right) F(\hat{v}) & \text { if } x \in\left(0, \beta_{1}^{a}(\bar{v})\right), \\ F(\hat{v}) & \text { if } x \in\left[\beta_{1}^{a}(\bar{v}), a\right), \\ F\left(\left(\beta_{2}^{a}\right)^{-1}(x)\right) & \text { if } x \in\left[a, \beta_{2}^{a}(\bar{v})\right] .\end{cases}
$$

The expected highest effort is given by

$W_{1}(a)=\int_{0}^{\beta_{2}^{a}(\bar{v})} x \mathrm{~d} G_{a}(x)=\beta_{2}^{a}(\bar{v})-\int_{0}^{\beta_{2}^{a}(\bar{v})} G_{a}(x) \mathrm{d} x$.

This expression is significantly less tractable than the expression for the average effort in (2). For our analysis of optimal head starts for $\gamma>0$, we will therefore impose a specific distributional assumption.

\section{The uniform case}

We henceforth assume, in accordance with (1), valuations to be uniformly distributed on [0, 1], i.e., $F(v)=v$. This implies $\hat{v}=\sqrt{a}$ and $\beta_{1}^{a}(v)=\beta_{2}^{a}(v)-a=\frac{1}{2} v^{2}-\frac{1}{2} a$ for $v>\hat{v}$. In the following, we first consider the problem of maximizing the expected highest effort $W_{1}(a)$. Then we turn to studying optimal head starts that maximize the general objective function $W_{\gamma}(a)$ with $\gamma \in[0,1]$.

\footnotetext{
3 For (irregular) type distributions that violate assumption (1), Kirkegaard (2012) finds that a small head start can be beneficial.
} 


\subsection{Expected highest effort}

Case 1: Consider $a \leq \beta_{1}^{a}(\bar{v})=\frac{1}{2}-\frac{1}{2} a$, i.e., $a \leq \frac{1}{3}$. For the uniform case, (3) reduces to

$G_{a}(x)= \begin{cases}\sqrt{2 x a+a^{2}} & \text { if } x \in[0, a), \\ \sqrt{4 x^{2}-a^{2}} & \text { if } x \in\left[a, \frac{1-a}{2}\right], \\ \sqrt{2 x-a} & \text { if } x \in\left[\frac{1-a}{2}, \frac{1+a}{2}\right] .\end{cases}$

Substituting this into (5) and noting that

$\frac{\mathrm{d}}{\mathrm{d} x}\left(\frac{1}{2} x \sqrt{4 x^{2}-a^{2}}-\frac{1}{4} a^{2} \ln \left[2 x+\sqrt{4 x^{2}-a^{2}}\right]\right)=\sqrt{4 x^{2}-a^{2}}$,

we obtain

$$
\begin{aligned}
W_{1}(a)= & \frac{1+a}{2}-\int_{0}^{a} \sqrt{2 x a+a^{2}} \mathrm{~d} x-\int_{a}^{\frac{1-a}{2}} \sqrt{4 x^{2}-a^{2}} \mathrm{~d} x \\
& -\int_{\frac{1-a}{2}}^{\frac{1+a}{2}} \sqrt{2 x-a} \mathrm{~d} x \\
= & \frac{1}{6}+\frac{1}{2} a-\frac{3^{\frac{3}{2}}-2}{6} a^{2}+\frac{1-5 a}{12} \sqrt{1-2 a} \\
& +\frac{1}{4} a^{2} \ln \left[\frac{1-a+\sqrt{1-2 a}}{(2+\sqrt{3}) a}\right]
\end{aligned}
$$

with the continuous extension $W_{1}(0)=\frac{1}{4}$.

Case 2: Consider $a \geq \frac{1}{3}$. For the uniform case, (4) reduces to

$G_{a}(x)= \begin{cases}\sqrt{2 x a+a^{2}} & \text { if } x \in\left[0, \frac{1-a}{2}\right), \\ \sqrt{a} & \text { if } x \in\left[\frac{1-a}{2}, a\right], \\ \sqrt{2 x-a} & \text { if } x \in\left[a, \frac{1+a}{2}\right] .\end{cases}$

Thus, (5) becomes

$$
\begin{aligned}
W_{1}(a)= & \frac{1+a}{2}-\int_{0}^{\frac{1-a}{2}} \sqrt{2 x a+a^{2}} \mathrm{~d} x \\
& -\int_{\frac{1-a}{2}}^{a} \sqrt{a} \mathrm{~d} x-\int_{a}^{\frac{1+a}{2}} \sqrt{2 x-a} \mathrm{~d} x \\
= & \frac{1}{6}+\frac{1}{6} \sqrt{a}+\frac{1}{2} a-\frac{7}{6} a^{\frac{3}{2}}+\frac{1}{3} a^{2} .
\end{aligned}
$$

Using expressions (6) and (7) for the contest designer's objective $W_{1}(a)$, we obtain the main result of this subsection.

Proposition 1. There is a unique $a^{*} \in\left(0, \frac{1}{3}\right)$ such that $W_{1}(a)$ is strictly increasing for all $a \in\left[0, a^{*}\right)$ and strictly decreasing for all $a \in\left(a^{*}, 1\right]$.

Proof. First, suppose $a \geq \frac{1}{3}$ and consider $W_{1}(a)$ given in (7). Notice that $W_{1}^{\prime}(a)<0$ for all $a \in\left[\frac{1}{3}, 1\right]$. Hence, if $W_{1}(a)$ has an internal maximum, the optimal head start has to satisfy $a^{*} \in\left(0, \frac{1}{3}\right]$.

Now, suppose $a \in\left[0, \frac{1}{3}\right]$. Note that $\frac{\mathrm{d}}{\mathrm{d} a} \ln \left[\frac{1-a+\sqrt{1-2 a}}{(2+\sqrt{3}) a}\right]=$ $-\frac{1}{a \sqrt{1-2 a}}<0$. Taking derivatives of (6), we obtain

$$
\begin{aligned}
W_{1}^{\prime}(a)= & \frac{1}{2}-\frac{3^{\frac{3}{2}}-2}{3} a-\frac{1}{2} \sqrt{1-2 a} \\
& +\frac{1}{2} a \ln \left[\frac{1-a+\sqrt{1-2 a}}{(2+\sqrt{3}) a}\right],
\end{aligned}
$$

$W_{1}^{\prime \prime}(a)=-\frac{3^{\frac{3}{2}}-2}{3}+\frac{1}{2} \ln \left[\frac{1-a+\sqrt{1-2 a}}{(2+\sqrt{3}) a}\right]$,

$W_{1}^{\prime \prime \prime}(a)=-\frac{1}{2 a \sqrt{1-2 a}}<0$.

Moreover, we have

$$
\begin{aligned}
& W_{1}^{\prime}(0)=\lim _{a \rightarrow 0} \frac{\ln \left[\frac{1-a+\sqrt{1-2 a}}{(2+\sqrt{3}) a}\right]}{\frac{2}{a}} \\
& =\lim _{a \rightarrow 0} \frac{-\frac{1}{a \sqrt{1-2 a}}}{-\frac{2}{a^{2}}}=\lim _{a \rightarrow 0} \frac{a}{2 \sqrt{1-2 a}}=0, \\
& W_{1}^{\prime}\left(\frac{1}{3}\right)=-\frac{9 \sqrt{3}-13}{18}<0, \\
& W_{1}^{\prime \prime}(0)=-\left(\sqrt{3}-\frac{2}{3}\right)+\lim _{a \rightarrow 0} \frac{1}{2} \ln \left[\frac{1-a+\sqrt{1-2 a}}{(2+\sqrt{3}) a}\right]=\infty \\
& W_{1}^{\prime \prime}\left(\frac{1}{3}\right)=-\left(\sqrt{3}-\frac{2}{3}\right)<0 .
\end{aligned}
$$

Consequently, since $W_{1}^{\prime \prime \prime}(a)<0$, there is a unique $\tilde{a} \in\left(0, \frac{1}{3}\right)$ such that $W_{1}^{\prime \prime}(a)>0$ for $a<\tilde{a}$ and $W_{1}^{\prime \prime}(a)<0$ for $a>\tilde{a}$. In turn, this implies that there is a unique $a^{*} \in\left(\tilde{a}, \frac{1}{3}\right)$ such that $W_{1}^{\prime}(a)>0$ for $a<a^{*}$ and $W_{1}^{\prime}(a)<0$ for $a>a^{*}$.

Numerically solving $W_{1}^{\prime}\left(a^{*}\right)=0$, we find the expected highest effort to reach its unique maximum at $a^{*} \approx 0.1586$. Hence, the contest designer finds it optimal to provide one player with a head start which is equal to roughly $\frac{1}{3}$ of the expected valuation $\left(\frac{1}{2}\right)$. Moreover, this leads to $\hat{v}=\sqrt{a} \approx 0.398$. Compared with the benchmark case where $a=0$, the highest $60 \%$ of the types of player 2 increase their bid, while the remaining types of player 2 and all types of player 1 decrease their bid.

\subsection{General objective function}

We are now ready to study the problem of maximizing the general objective function $W_{\gamma}(a)=\gamma W_{1}(a)+(1-\gamma) W_{0}(a)$. According to Proposition $1, W_{1}$ is first increasing and then decreasing in $a$ whereas we know from Section 2 that $W_{0}$ is decreasing for all $a$. In the uniform case, the expected average effort given in (2) reduces to

$W_{0}(a)=\frac{1}{6}-\frac{1}{6} a^{\frac{3}{2}}$.

The next proposition shows that for all $\gamma<1$ small head starts result in a lower $W_{\gamma}$ than no head start. However, if the weight on the highest expected effort is sufficiently large, a large head start is optimal.

Proposition 2. For all $\gamma \in[0,1)$, there is an $\epsilon>0$ such that $W_{\gamma}(a)<W_{\gamma}(0)$ for all $a \in(0, \epsilon)$. Moreover, there is $a \bar{\gamma} \in(0,1)$ such that $a^{*}(\gamma)=0$ for all $\gamma \in[0, \bar{\gamma})$ and $a^{*}(\gamma)>0$ for all $\gamma \in(\bar{\gamma}, 1]$.

Proof. Consider $\gamma \in[0,1)$ and recall that $W_{\gamma}(a)=\gamma W_{1}(a)+$ $(1-\gamma) W_{0}(a)$. Using $(10)$ and $W_{0}^{\prime}(a)=-\frac{1}{4} a^{\frac{1}{2}}$, we find $W_{\gamma}^{\prime}(0)=0$. Observe that

$$
\begin{aligned}
\lim _{a \rightarrow 0} \sqrt{a} \ln \left[\frac{1-a+\sqrt{1-2 a}}{(2+\sqrt{3}) a}\right] & =\lim _{a \rightarrow 0} \frac{\ln \left[\frac{1-a+\sqrt{1-2 a}}{(2+\sqrt{3}) a}\right]}{\frac{1}{\sqrt{a}}} \\
& =\lim _{a \rightarrow 0} \frac{-\frac{1}{a \sqrt{1-2 a}}}{-\frac{1}{2} a^{-\frac{3}{2}}}=0 .
\end{aligned}
$$




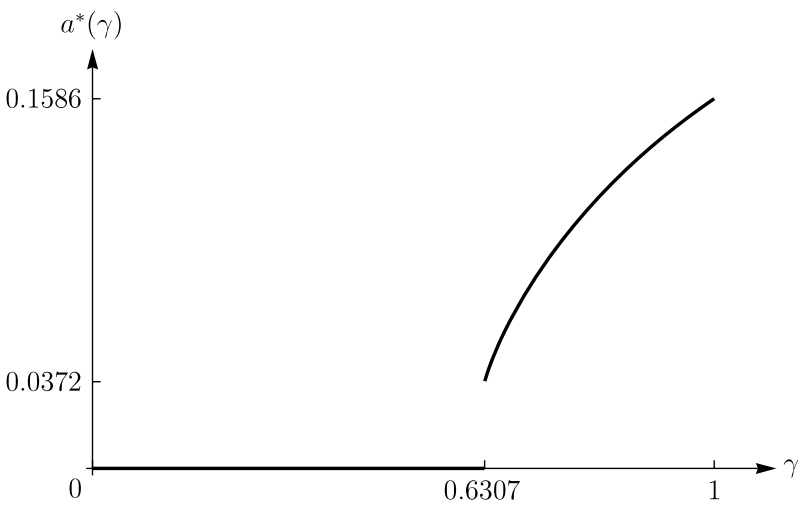

Fig. 1. The optimal head start $a^{*}(\gamma)$ for all $\gamma \in[0,1]$.

Therefore, using $(8)$ and $W_{0}^{\prime \prime}(a)=-\frac{1}{8} a^{-\frac{1}{2}}$, we obtain

$$
\begin{aligned}
W_{\gamma}^{\prime \prime}(0)= & -\gamma \frac{3^{\frac{3}{2}}-2}{3} \\
& +\lim _{a \rightarrow 0}\left(\gamma \frac{1}{2} \ln \left[\frac{\left.1-a+\sqrt{1-2 a}]-\frac{(1-\gamma)}{8 \sqrt{a}}\right)}{(2+\sqrt{3}) a}\right]\right. \\
= & -\gamma \frac{3^{\frac{3}{2}}-2}{3}+\lim _{a \rightarrow 0} \frac{\gamma 4 \sqrt{a} \ln \left[\frac{1-a+\sqrt{1-2 a}}{(2+\sqrt{3}) a}\right]-(1-\gamma)}{8 \sqrt{a}} \\
= & -\infty .
\end{aligned}
$$

Thus, for all $\gamma \in[0,1)$, there is an $\epsilon>0$ such that $W_{\gamma}(a)<W_{\gamma}(0)$ for all $a \in(0, \epsilon)$.

It remains to prove the second statement in the proposition. Observe that

$$
\begin{aligned}
W_{\gamma}(a)-W_{\gamma}(0)= & \gamma\left(W_{1}(a)-W_{1}(0)\right) \\
& +(1-\gamma)\left(W_{0}(a)-W_{0}(0)\right),
\end{aligned}
$$

where $W_{0}(a)-W_{0}(0)<0$ for all $a>0$. Hence, if for a given $\gamma$ there is an $a$ such that $W_{\gamma}(a)>W_{\gamma}(0)$, then $W_{\tilde{\gamma}}(a)>W_{\tilde{\gamma}}(0)$ for all $\tilde{\gamma} \geq \gamma$. Thus, $a^{*}(\tilde{\gamma})>0$ for all $\tilde{\gamma} \geq \gamma$. Consequently, there is a $\bar{\gamma} \in[0,1]$ such that $a^{*}(\gamma)=0$ for all $\gamma<\bar{\gamma}$ and $a^{*}(\gamma)>0$ for all $\gamma>\bar{\gamma}$. We are left to show that $\bar{\gamma} \in(0,1)$.

By Proposition $1, W_{1}(a)>W_{1}(0)$ for some $a>0$. Since $W_{\gamma}(a)-W_{\gamma}(0)$ is continuous in $\gamma($ see $(11)), W_{\gamma}(a)>W_{\gamma}(0)$ for some $\gamma<1$ and hence $\bar{\gamma}<1$.

From $(9)$ and $W_{0}^{\prime \prime \prime}(a)=\frac{1}{16} a^{-\frac{3}{2}}$, we obtain

$W_{\gamma}^{\prime \prime \prime}(a)=-\gamma \frac{1}{2 a \sqrt{1-2 a}}+(1-\gamma) \frac{1}{16} a^{-\frac{3}{2}}$.

Suppose $\gamma \leq \frac{1}{9}$ which yields $W_{\gamma}^{\prime \prime \prime}(a) \geq \frac{1}{18 a}\left(\frac{1}{\sqrt{a}}-\frac{1}{\sqrt{1-2 a}}\right) \geq 0$ for all $a \in\left[0, \frac{1}{3}\right]$. Hence, $W_{\gamma}^{\prime \prime}\left(\frac{1}{3}\right)<0$ implies $W_{\gamma}^{\prime \prime}(a)<0$ for all $a \in\left[0, \frac{1}{3}\right]$. In turn, $W^{\prime}(0)=0$ implies $W_{\gamma}^{\prime}(a)<0$ for all $a$. Consequently, $a^{*}(\gamma)=0$ for all $\gamma \in\left[0, \frac{1}{9}\right]$ and hence $\bar{\gamma}$ $>0$.

According to Proposition 2, there is a critical value $\bar{\gamma}$ above which the designer finds it optimal to introduce a strictly positive head start. Numerical simulation yields $\bar{\gamma} \approx 0.6307$. Fig. 1 depicts the optimal head start as a function of $\gamma$, which, in line with the proposition, is discontinuous at $\bar{\gamma}$.

\section{Conclusion}

According to conventional wisdom, the main reason for biasing a contest is to reduce the heterogeneity among contestants in order to elicit more aggregate effort. We offer a different explanation for introducing a bias: in an all-pay auction with symmetric contestants a head start can be beneficial if the designer is (at least partially) interested in the expected highest effort. Rather than being a choice variable, the head start could also represent a (behavioral) bias of a jury in favor of one contestant. In this interpretation, a biased jury may lead to a higher expected highest effort than an unbiased jury.

By considering head starts, we have focused on one specific instrument with which the designer can influence the outcome of a contest. A promising avenue for future research is to allow for more general instruments in optimal asymmetric contest design for maximizing the expected highest effort.

\section{Acknowledgments}

We thank David Pérez-Castrillo for very helpful comments. Wasser gratefully acknowledges financial support from the Deutsche Forschungsgemeinschaft through SFB/TR 15.

\section{References}

Clark, D.J., Riis, C., 2000. Allocation efficiency in a competitive bribery game. J. Econ. Behav. Organ. 42 (1), 109-124.

Franke, J., Kanzow, C., Leininger, W., Schwartz, A., 2014. Lottery versus all-pay auction contests: a revenue dominance theorem. Games Econom. Behav. 83, $116-126$.

Kawamura, K., Moreno de Barreda, I., 2014. Biasing selection contests with ex-ante identical agents. Econom. Lett. 123 (2), 240-243.

Kirkegaard, R., 2012. Favoritism in asymmetric contests: head starts and handicaps. Games Econom. Behav. 76 (1), 226-248.

Konrad, K.A., 2002. Investment in the absence of property rights; the role of incumbency advantages. Eur. Econ. Rev. 46 (8), 1521-1537.

Lazear, E.P., Rosen, S., 1981. Rank-order tournaments as optimum labor contracts. J. Polit. Econ. 89 (5), 841-864.

Pérez-Castrillo, D., Wettstein, D., 2013. Innovation contests. Working paper, Universitat Autònoma de Barcelona.

Seel, C., 2014. The value of information in asymmetric all-pay auctions. Games Econom. Behav. 86, 330-338.

Siegel, R., 2014. Asymmetric contests with head starts and non-monotonic costs. Amer. Econ. J.: Microecon., forthcoming. 